\title{
GALILEO E A DEFESA DA COSMOLOGIA COPER- NICANA: A SUA VISÃO DO UNIVERSO
}

\author{
Júlio César Penereiro \\ Centro de Ciências Exatas Ambientais e de Tecnologias \\ PUC-Campinas \\ Departamento de Raios Cósmicos e de Cronologias - IFGW \\ UNICAMP \\ Campinas - SP
}

\begin{abstract}
Resumo
No presente trabalho estudamos o desencontro do argumento de Galileo Galilei relativo à rotação da Terra, contida na obra "Diálogo sobre os dois máximos sistemas do mundo - ptolomaico e copernicano". Apresentamos algumas descobertas astronômicas realizadas por Galileo e suas consequências para com a ordenação do universo. Uma discussão sobre o método científico intuído por ele é apresentada, cuja intenção é a de encorajar todos a pensar sobre como a observação do cosmos feita por Galileo nos forçou a reconsiderar nossa compreensão do mundo. Em adição, gostaríamos de ajudar a responder algumas questões básicas em física e astronomia.
\end{abstract}

Palavras-chave: Teoria copernicana; Galileo Galilei; História da Ciência.

\begin{abstract}
In the present work we study the mismatch of the argument of Galileo Galilei about the Earth's rotation, which is in the book "Dialogue concerning the two chief world systems - ptolomaic
\end{abstract}

\footnotetext{
${ }^{+}$Galileo and the defence of the cosmology's copernician: his view of the Universe

* Recebido: março de 2008.

Aceito: outubro de 2008.
}

Cad. Bras. Ens. Fís., v. 26, n. 1: p. 173-198, abr. 2009. 
and copernican". We present some astronomical discoveries by Galileo and its consequences to understand the universe's ordination. One discussion about the scientific methods intuid by him is presented, with the aim to encourage us all to think about how Galileo's observation of the cosmos force us to reconsider our understanding of the world. In addition we would like to help answering some basic questions in physics and astronomy.

Keywords: Copernican teories; Galileo Galilei; History of Science.

\section{Introdução}

Em 1597, numa carta à Johannes Kepler, Galileo Galilei se confessa adepto ao trabalho escrito por Nicolaj Kopernik - As revoluções do orbes celestes (COPÉRNICO, 1984) - desde há alguns anos, embora não estivesse disposto a entrar na contenda para defendê-la publicamente, receando ser alvo de críticas e cair no ridículo.

No ano de 1632, Galileo publicou uma obra com a qual tinha sonhado durante muito tempo. Trazia um título muito comprido, mas normal para a época: Diálogo de Galileo Galilei linceu, matemático extraordinário do Estúdio de Pisa e filósofo e matemático primário do Sereníssimo Grão-Duque da Toscana; onde, nas reuniões de quatro jornadas, discorre-se sobre os dois máximos sistemas do mundo - ptolemaico e copernicano - propondo de maneira indeterminada as razões filosóficas e naturais tanto para uma quanto para a outra parte (GALILEI, 2004).

O "Diálogo", embora não seja a obra mais madura de Galileo, é a mais célebre e conhecida. Como a primeira palavra do título sugere, a obra é um diálogo, isto é, uma conversa, em que participam três personagens. O primeiro é Filippo Salviati, gentil-homem florentino e acadêmico linceu. O segundo, devido ao seu grande interesse pelas exposições sobre a física e o Tratado do Céu de Aristóteles (ARISTÓTELES, 1984), traz o nome de Simplício (célebre comentador grego). O terceiro é Giovan Francesco Sagredo, um veneziano, em cujo palácio na cidade italiana de Veneza tem lugar o diálogo. Na conversa, Salviati é o porta-voz de Galileo, que é referido como o nosso acadêmico. Simplício representa a ciência aristotélico-ptolemaica tradicional. Sagredo é um homem inteligente e culto não especialista, sendo o mediador entre os dois. Vale ressaltar que o diálogo (a con- 
versa) entre Sagredo, Salviati e Simplício nunca ocorreu em local algum, mesmo por que Salviati e Sagredo já tinham falecido há algum tempo e Simplício há muito tempo quando Galileu concebeu a obra.

O conjunto do "Diálogo" é dividido em quatro partes (jornadas), precedidas de um prefácio e de uma dedicatória endereçada a Ferdinando II de Medici, grão-duque da Toscana. Resumidamente, a Primeira Jornada discute a concepção geral do universo, refutando sobretudo a ideia antiga e medieval de um mundo de dois andares, em que o mundo terrestre teria características e leis diferentes do mundo celeste, isto é, onde estão contidos os astros. A Segunda Jornada focaliza, especialmente, as experiências terrestres que visavam estabelecer a imobilidade da Terra. Galileo procura desqualificá-las, mostrando como tais experiências nada provam, pois os fatos de experiência continuam os mesmos, quer se suponha que a Terra está imóvel, quer se suponha que ela gira em torno do seu eixo em 24 horas. A Terceira Jornada refere-se ao exame dos fenômenos celestes que confirmam o movimento anual da Terra em torno do Sol. Finalmente, a Quarta Jornada, a mais importante aos olhos do autor, mostra como as marés seriam impossíveis na hipótese de uma Terra estacionária, sendo explicáveis supondo-se o duplo movimento, diurno e anual da mesma.

Trinta e seis anos mais tarde, em 1633, Galileo enfrentava o Tribunal do Santo Ofício (Inquisição) romano por ter defendido, no "Diálogo", aquelas mesmas teses que, na juventude, o deixaram praticamente indiferente (CAVALCANTE, 1989).

Neste trabalho, caracterizaremos as etapas sucessivas que levaram Galileo a uma convicção tão profunda e tão sincera que sua afirmação o levou a arriscar a própria vida.

Evidentemente, se o Galileo de 1597 se recusava a defender o copernicianismo, era porque a nova cosmologia heliocêntrica ainda não tinha provas suficientes para persuadir, embora ela fosse preferível, aos seus olhos e por razões de simplicidade, à doutrina ptolemáica.

A partir de 1609 , as descobertas astronômicas realizadas com o telescópio (perspicillum - designação em latim usada por Galileo para nomear o primeiro telescópio), forneciam ao próprio Galileo argumentos novos e, a seu ver, decisivos em favor do copernicianismo. Em que pese as dificuldades que os equipamentos por ele construídos tinham (o primeiro aumentava apenas nove vezes; o segundo, trinta vezes, e já era superior a qualquer outro até então fabricado), para que tirasse provas conclusivas a respeito de todas as suas observações. 
O caminho para a conversão própria, e para a convicção dos incrédulos, estava aberto. Porém, antes de segui-lo até as suas últimas consequências, restava preencher três condições:

- em primeiro lugar, libertar-se do princípio de autoridade representado, por um lado, pelas Sagradas Escrituras (Bíblia) e, por outro, pela tradição aristotélica;

- a seguir, elaborar novas premissas que tornassem possível uma nova cosmologia: isso significava, evidentemente, a derrubada das premissas aristotélicas;

- finalmente, construir uma mecânica compatível com o heliocentrismo e, particularmente, com o movimento diurno da Terra.

A tarefa era gigantesca e veremos que Galileo não teve forças suficientes para completá-la, deparando-se com dificuldades que, para nós, parecem tão triviais (MARTINS, 1984; PEDUZZI, 1991). No entanto, a evolução do pensamento científico de Galileo durante aquelas três décadas no caminho da conversão do copernicianismo foi decisiva para a maturação e a elaboração da sua obra puramente científica publicada em 1638, coroada pelos Discurso e demonstrações matemáticas acerca de duas novas ciências, ou como é geralmente conhecido pelas suas três últimas palavras: "Duas Novas Ciências" (GALILEI, 1985).

É exatamente isso que torna essa evolução de pensamento particularmente interessante para o cientista e a história da ciência, mesmo porque, consideramos que, com a publicação do "Diálogo", inaugurava-se a ciência moderna e redesenhava-se o mapa da cultura ocidental.

Embora vários pontos da obra de Galileo já tenham sido estudados por muitos pesquisadores (HALL, 1988; KOYRÉ, 1992; KUHN, 1990; KOESTLER, 1989), neste trabalho analisaremos com cuidado um importante aspecto da obra "Diálogo": os seus argumentos relacionados ao movimento circular e aos movimentos da Terra.

Também verificaremos pontos conceituais delicados e fundamentais para os professores do ensino de ciências, na atualidade. Do ponto de vista didático, esses temas mostram as dificuldades encontradas por Galileo em sua época e são importantes para o professor discutir com seus estudantes. Mesmo porque, a compreensão dessas dificuldades pode auxiliar o professor de ciências e de física, que deve ser capaz de compreender as dúvidas dos estudantes, e discutir os conceitos envolvidos nesse tema de forma mais aprofundada. 


\section{As descobertas astronômicas e suas consequências}

Costuma-se dizer que Galileo inventou o telescópio (ou a luneta), mas não é verdade. Acredita-se que seu inventor tenha sido o fabricante de óculos holandês Hans Lippershey, em 1608. No ano seguinte, em Veneza na Itália, chega ao conhecimento de Galileo que um instrumento "fazia aparecer muito próximos os objetos mais afastados". Galileo decide imediatamente construir um equipamento semelhante (KOYRE, 2006). Ele fixa uma lente plano-côncova e outra planoconvexa às extremidades de um tubo de chumbo e observa que, utilizando-se a lente plano-côncova como ocular, os objetos são "sensivelmente aumentados e aproximados".

Depois de apresentar o instrumento às autoridades de Veneza, Galileo dirige o telescópio para o céu e, a partir do outono de 1609, sucedem-se as mais extraordinárias descobertas do mundo científico.

As primeiras descobertas astronômicas de Galileo foram publicadas em 1610, na obra Sidereus Nuncius ("A Mensagem das Estrelas", (GALILEI, 1987)) e estão relatadas resumidamente a seguir. Apresentamos essas descobertas não necessariamente por ordem cronológica, mas por ordem de exposição pelas consequências que elas iriam desencadear.

\section{II.1 O relevo da Lua}

Alguns dias depois da conjunção (Lua Nova), Galileo observa que a linha de demarcação entre a zona iluminada e a zona obscura apresenta irregularidades. Continuando a observar a zona iluminada à medida que a Lua se aproxima da quadratura (Quarto Crescente), ele nota pequenas regiões de sombra, análogas às sombras projetadas por cumes montanhosos nos vales ou nas planícies que eles dominam. Galileo observa também que essas zonas de sombra diminuem à medida que os raios solares incidem mais perpendicularmente sobre a superfície lunar.

Com isso, ele conclui sobre a existência de um relevo lunar semelhante, em parte, ao relevo terrestre. Dissipa-se, assim, o mito aristotélico de uma Lua perfeitamente esférica e polida. (Recordemos que, na época, somente a forma esférica perfeita convinha aos corpos celestes).

\section{II.2 As manchas solares}

Em julho de 1610, ao observar o Sol, Galileo nota a presença de manchas escuras no disco solar. Durante dois anos Galileo volta periodicamente à observação dessas manchas e endereça três cartas a Marco Welser, no final de 1611, nas 
quais relata suas observações. Em 1613, publica suas impressões na forma de livro, com o título História e demonstração em torno das manchas solares. Na obra, discute, em primeiro lugar, que as manchas se deslocam de oeste para leste, paralelamente ao equador solar, percorrendo a largura do disco em mais ou menos 14 dias. Em segundo lugar, as manchas não têm uma forma fixa, nem uma existência permanente, com algumas desaparecendo no decorrer do trânsito e outras se dividindo em várias manchas menores ou várias delas se juntando para formar uma mancha maior (para análises mais circunstanciadas da polêmica sobre as manchas solares, vide os trabalhos de SHEA, 1992 e CLAVELIN, 1996).

Galileo conclui que as manchas pertencem à superfície do Sol e que este gira em torno de seu eixo em 28 dias aproximadamente. De modo que, contrariamente ao que ensinava a doutrina aristotélica, um corpo celeste está sujeito a mudanças, a "gerações" (aparecimento das manchas) e a "corrupções" (desaparecimento das manchas).

\section{II.3 As fases de Vênus}

A partir do mês de outubro de 1610, Galileo observa sistematicamente Vênus e descobre que o planeta apresenta fases semelhantes às fases da Lua, e conclui que:

- Vênus gira efetivamente em torno do Sol;

- Vênus, um planeta, não tem luminosidade própria. Escreve ele, na carta datada em 30 de dezembro de 1610, ao Pe. Cristóvão Clavius que: “.... estou certo de que os planetas não têm luminosidade própria, e somente brilham quando iluminados pelo Sol, o que é o caso, creio eu, das estrelas fixas ..." (GALILEI, 2004, p. 601).

Portanto, a Lua, Vênus e, por extensão, todos os planetas, têm algo mais em comum com a Terra. Nenhum desses corpos celestes possui luminosidade própria. Todos eles, como a Terra, somente refletem e espalham a luz que recebem do Sol.

As descobertas do relevo da Lua, das manchas solares e das analogias entre os planetas e a Terra levam Galileo, então, a rejeitar de vez, na base da observação, a hierarquia do cosmos aristotélico. $\mathrm{O}$ mundo supralunar não é nem mais nem menos "nobre" que o mundo sublunar. Como este, ele é também sujeito a mudanças. O obstáculo aristotélico "substancial", que dava aos corpos celestes um comportamento, a priori, diferente do comportamento dos corpos terrestres, desaparece e, a partir de agora, Galileo pode aceitar racionalmente que a Terra seja incluída entre os planetas de um sistema heliocêntrico. 
Em seguida, novas descobertas com o uso do telescópio vão pender ainda mais a balança para o lado do heliocentrismo.

\section{II.4 Os satélites de Júpiter}

Em janeiro de 1610, Galileo observa Júpiter e descobre os seus quatro maiores satélites, aos quais ele dá o nome de "planetas mediceanos", em homenagem ao grão-duque da Toscana.

Ele acabara de observar em Júpiter algo semelhante ao que ocorre com o sistema solar, isto é, os satélites orbitando o planeta em tempos diferentes segundo suas órbitas. Assim, finalmente, tem a "prova" de que a Terra não é necessariamente o centro do universo, já que corpos celestes giram em torno de um dos planetas.

A existência observada dos satélites de Júpiter é um argumento de peso, embora indireto, a favor do heliocentrismo.

\section{II.5 As observações de Marte, Vênus e Mercúrio}

Desde Ptolomeu sabia-se que Marte em oposição é mais brilhante que em qualquer outra ocasião, porém, a olho nu, tratava-se ainda de um objeto pontual. Galileo observa Marte com o telescópio e, então, vê que não se trata de um ponto brilhante e sim de um disco e que, quando o planeta está em oposição, esse disco é não somente mais brilhante, como também muito maior que na época da conjunção.

Da mesma forma, Vênus é seis vezes maior na época da conjunção superior (Terra - Sol - Vênus) do que na conjunção inferior (Terra - Vênus - Sol). O mesmo fenômeno, porém em escala diferenciada, acontece com o planeta Mercúrio.

Esses fatos são evidentemente previstos pela teoria heliocêntrica, tanto para Copérnico, como para Kepler, eles eram meras conjecturas que deveriam se verificar caso a teoria heliocêntrica estivesse certa, mas que ainda não tinham sido comprovadas pela observação.

Em 1613, depois da publicação de "A Mensagem das Estrelas" e das "Cartas sobre as manchas solares" (GALILEI, 1987), Galileo está convicto da veracidade da teoria heliocêntrica. A conversão total exigiria, no entanto, o rompimento com toda uma tradição de autoridade imposta. 


\section{II.6 As observações de Saturno}

Em 1623, a Academia dos Lincéus publica $O$ Ensaiador (Il Saggiatore), obra que Galileo dedica ao Papa Urbano VIII (seu amigo, Mafeo Barberini). Nesse trabalho, ele deixa claro que, a Matemática é a linguagem da Física que, naquele tempo, começava a se constituir com maior rigor. Dentre outras coisas, em suas observações realizadas no verão-outono de 1610, relata que o mais elevado dos planetas (Saturno) tem forma trigêmea. O telescópio de Galileo não tinha a resolução necessária que lhe permitisse descobrir os anéis de Saturno (isso só foi "resolvido" em 1659 pelo astrônomo holandês Christiaan Huygens). Galileo achava que Saturno tinha duas pequenas luas em lados opostos, e bem próximas do planeta, dando aparência de "um planeta com um par de orelhas" (GALILEI, 1973).

\section{A rejeição do princípio de autoridade}

O princípio de autoridade é a aceitação cega dos ensinamentos das Sagradas Escrituras; é também o Magister dixit (do latim, O mestre disse). É preciso não subestimar o peso que esses mandamentos tinham na época, mas Galileo devia libertar-se deles. Resumidamente, ele escreveu a respeito desses mandamentos afirmando:

\section{1. Autoridade das Escrituras}

Em três cartas célebres, Galileo contesta que se dê às Escrituras Santas uma interpretação literal nos assuntos de filosofia natural, isto é, no estudo da natureza. Essas cartas são, respectivamente, de 21 de dezembro de 1613 (ao Cardeal Benedetto Castelli), de 23 de março de 1615 (à grã-duquesa de Toscana) e de 16 de agosto de 1631 (a Elia Diodati).

$\mathrm{O}$ argumento de Galileo é o seguinte:

... todo mundo sabe que mesmo em questões de fé, as Escrituras deixam às vezes de traduzir literalmente o verbo divino. Para que as massas ignorantes, o povo inculto, possam entender os mandamentos de Deus, as Escrituras recorrem muitas vezes a parábolas, comparações, a analogias nem sempre explícitas, mas que, se fossem ao pé da letra, conduziriam a verdadeiras heresias. Elas chegariam a mostrar...

Diz Galileo: 
... um Deus irado, ou vingador e maldoso, o que não corresponde evidentemente à realidade.

Entretanto, se as Escrituras não devem ser interpretadas literalmente em certas questões que tocam a fé, por que haveríamos de seguí-las ao pé da letra em questões de filosofia natural?

Galileo dá-se mesmo ao luxo de mostrar que certas interpretações, que eram apresentadas como argumentos contra o heliocentrismo, na realidade são argumentos a favor dele.

De qualquer maneira, Galileo recomenda que, no estudo do universo, se observe primeiro o que acontece, e que se tente uma interpretação racional das observações, utilizando-se assim os sentidos e a inteligência que o próprio Criador nos confiou. Ele insiste em que se observe a natureza, em vez de apegar-se às Escrituras:

“Será (...) que a Obra é menos augusta que o Verbo?”, pergunta ele.

\section{2 Autoridade de tradição aristotélica}

Rejeitando, de início, o enciclopedismo da doutrina aristotélica, Galileo afirma claramente que o homem deve limitar-se aos seus objetivos, quando se propõe a estudar o universo. Pela primeira vez, alguém entende que o conhecimento da natureza pelo homem é necessariamente limitado. Somente Deus tem a infinita capacidade de tudo compreender instantaneamente. Na Primeira Jornada do "Diálogo" (GALILEI, 2004), Salviati afirma que:

... os mais sábios reconhecem espontaneamente que a ciência que eles possuem é infima.

Quanto à autoridade do próprio Aristósteles, Galileo tenta convencer aos seus interlocutores que o Mestre não era infalível e que ele mesmo, com sua vasta inteligência e sabedoria, seria o primeiro a reconhecer os seus erros, se fosse confrontado com a evidência das observações. Neste aspecto, verifiquemos o que Salviati diz a Simplício, na Segunda Jornada do "Diálogo":

... dizei-me, por favor, sois tão ingênuo que não entendeis que se Aristóteles tivesse estado presente escutando o doutor que o queria fazer autor do telescópio, teria discutido muito com ele que com todos aqueles que riam do doutor e de suas interpretações? Duvidais talvez que Aristóteles, se visse as novidades descobertas no céu, não mudaria de opinião, corrigindo seus livros, para aproxi- 
mar-se de doutrinas mais sensiveis, afastando de si aqueles tão pobres de juizo que muito pusilanimemente insistem em querer sustentar cada uma de suas afirmações, sem entender que Aristóteles, quando fosse tal e qual eles o imaginam, seria cérebro indócil, uma mente obstinada, um espirito repleto de barbárie, uma vontade tirânica, que, reputando todos os outros como estúpidos carneiros, quisesse que seus decretos fossem antepostos aos sentidos, às experiências, à própria natureza? São os seguidores de Aristóteles que outorgaram a autoridade a Aristóteles, e não ele mesmo que a usurpou ou tomou; e, porque é mais fácil ocultar-se debaixo do escudo de outrem que comparecer de viso aberto, temem e nem se aventuram a afastar-se somente um passo, e antes de alterar alguma coisa no céu de Aristósteles, querem impertinentemente negar aquelas coisas que vêem no céu da natureza (GALILEI, 2004, p. 191).

Vejamos que Simplício pergunta:

Mas quando se abandona Aristóteles, quem poderia ser nosso guia na filosofia? Designai algum autor (GALILEI, 2004, p. 193).

Salviati responde:

É necessário um guia nos países desconhecidos e selvagens, mas nos lugares abertos e planos somente os cegos necessitam de guia; e quem é assim deve ficar em casa, mas quem tem os olhos na fronte e na mente deve servir-se deles como guia (GALILEI, 2004, p. 193).

E quando se discute ou se estuda algum fenômeno natural, Salviati pede aos aristotélicos que:

Por isso, Sr. Simplício, apresentai as razões e as demonstrações, vossas ou de Aristóteles, e não com textos e meras autoridades, porque nossos discursos hão de ser sobre o mundo sensivel, e não sobre um mundo de papel (GALILEI, 2004, p. 194).

Tendo-se libertado do manto pesado da autoridade e da tradição, Galileo está pronto a empreender a tarefa de construção de uma cosmologia coperniciana. 


\section{As três premissas cosmológicas}

As descobertas astronômicas já haviam convencido Galileo que a hierarquia "substancial" ou "essencial" de Aristóteles é inexistente. Todo o universo visível ao telescópio - é, pensa ele, submetido às mesmas regras (as mesmas leis, diríamos hoje); consequentemente, a física terrestre poderá ser utilizada para tirar conclusões a respeito dos fenômenos celestes.

Galileo abandona o mito de um cosmos hierárquico, mas também, como Copérnico e Kepler, acredita numa ordem universal. Diz ele na Primeira Jornada do "Diálogo":

... e admito que o mundo seja um corpo dotado de todas as dimensões e, por isso mesmo, perfeitíssimo; e acrescento que como tal é necessariamente ordenadíssimo, ou seja, formado de partes dispostas entre si com máxima e perfeitíssima ordem, conclusão que não creio poder ser negada nem por vós, nem por outros (GALILEI, 2004, p. 99).

A primeira premissa cosmológica é, pois, a de um universo ordenado.

Esse universo é finito ou infinito? Observando a Via Láctea, Galileo nota que o leve véu que a caracteriza para um observador sem instrumento, se resolve no telescópio, numa infinidade de estrelas. Ele conclui corretamente que essas estrelas são mais afastadas que as outras, visíveis a olho nu (GALILEI, 1987). Em consequência, a "esfera das estrelas fixas" tem uma certa profundidade, uma certa espessura. De quanto é essa profundidade? Em outros termos, pode-se afirmar que o mundo é finito, como quer a tradição aristotélica, e com ela, Copérnico e Kepler? Ou que ele é infinito, como queria Giordano Bruno? Galileo não se pronuncia a esses questionamentos, ou seja, ele não conclui por falta de provas suficientes. $\mathrm{O}$ telescópio lhe permite afirmar que o universo é mais extenso do que se acreditava, mas nada prova que ele seria infinito.

No universo galileano ordenado, mas sem hierarquia, os fenômenos naturais não se explicam mais pelas qualidades "substanciais" ou "essenciais" dos corpos. Não havendo mais a preponderância da "essência", o conceito de lugar próprio perde o seu conteúdo. Assim, assistimos com Galileo a uma democratização do espaço. Qualquer coisa pode se encontrar em qualquer lugar.

Essa democratização do espaço físico é a segunda premissa cosmológica galileana. A Terra, em particular, pode ser tratada como qualquer outro planeta: ela não tem mais a necessidade ontológica de permanecer no centro do universo. 
Tendo rejeitado o mito das "essências" e, com ele, o mito dos "lugares próprios", Galileo se sente forçado a rever também o conceito tradicional de movimento. Recordemos que, na doutrina aristotélica, o movimento era um processo transitório que levava um "ser em potência" para o lugar natural, onde ele se "realizava"; o repouso no lugar natural, ao contrário, era um estado.

Galileo insiste primeiro em mostrar que não há diferença essencial entre repouso e movimento, sendo que ele faz isso de um modo extremamente interessante, na Primeira Jornada do "Diálogo", mostrando que um corpo que se deixa cair, adquire de maneira contínua todos os "graus" de velocidade a partir do repouso. Galileo conclui que o "grau a partir do qual o móvel inicia o seu movimento é o da extrema lentidão, isto é, do repouso". Ele estabelece isso através de Salviati, quando afirmava que:

... Por ter esta inclinação, nasce necessariamente que ele (um corpo), no seu movimento, acelerar-se-á continuamente e, começando com um movimento lentíssimo, não adquirirá grau algum de velocidade, antes de ter passado por todos os graus menores de velocidade, ou poderíamos dizer, de maior lentidão: porque, partindo do estado de repouso (que é o grau de infinita lentidão do movimento), não existe razão alguma pela qual ele deva entrar num determinado grau de velocidade, antes de entrar num grau menor, e em outro ainda menor antes que aquele; pelo contrário, parece perfeitamente razoável passar antes pelos graus mais próximos daquele do qual partiu, e daqueles aos mais afastados; mas o grau a partir do qual o móvel começa a mover-se é aquele da máxima lentidão, ou seja, do repouso (GALILEI, 2004, p. 100).

Do ponto de vista ontológico está assim estabelecida à equivalência conceitual entre movimento e repouso e, portanto, a indiferença de qualquer corpo para com um outro desses estados. É esta a terceira premissa cosmológica de Galileo.

Assim, ele tinha diante dos olhos um universo em que os corpos podiam, indiferentemente, permanecer em repouso em qualquer lugar, ou movimentar-se em qualquer direção.

Desta forma, podemos dizer que a primeira premissa exigia de Galileo uma ordenação deste universo. 


\section{A ordenação do universo através do movimento circular}

Aproveitando o que poderíamos chamar de a "democratização do universo", Galileo vai transpor para a escala cósmica os resultados das experiências que ele efetua na Terra. Esse passo foi fundamental para o seu raciocínio e de enorme importância para o futuro da ciência.

Do ponto de vista da física contemporânea, essas experiências são muito simples e dizem respeito ao comportamento dos corpos frente à gravidade. Mas, o que vinha a ser gravidade para Galileo? No seu entendimento, gravidade era um atributo da matéria. Certamente, uma força, mas uma força pertencente ao corpo, permanente nele, agindo do interior e obrigando-o a se movimentar em direção ao centro da Terra, o "centro comum dos graves".

Assim, o conceito galileano de gravidade é muito próximo do conceito coperniciano, embora mais evoluído.

Partindo dessa concepção, Galileo observa a queda dos corpos, livremente ou sobre planos inclinados. Suas observações e conclusões se encontram dispersas em toda a sua obra "Diálogo" (GALILEI, 2004). Naturalmente elas o levarão à lei da queda dos corpos. Assim, na obra "Cartas sobre as manchas solares" (GALILEI, 1987), Galileo diz:

Observei que (...) os graves têm inclinação para o movimento de descida, esse movimento sendo executado por eles por meio de uma propriedade intrínseca, e sem necessidade de um motor externo, todas as vezes que não se acham impedidos por algum obstáculo.

Pelo contrário (...) esses mesmos corpos têm repugnância para o movimento de subida, de modo que eles nunca se movem dessa maneira, a menos que sejam projetados violentamente por um motor externo.

E, conclui:

Eles são indiferentes em relação ao movimento horizontal, para o qual não têm nem inclinação nem repugnância.

Notamos que o que Galileo entende por movimento horizontal é o movimento sobre uma superfície esférica, cujos pontos são equidistantes do centro comum dos graves. Portanto, continua ele: 
... todos os impedimentos tendo sido removidos, um grave colocado sobre uma superficie esférica concêntrica com a Terra será indiferente ao repouso ou ao movimento (...) e permanecerá no estado em que terá sido colocado. Isto é, se colocado em repouso permanecerá assim. E se posto em movimento para Oeste por exemplo, manterá o movimento. Assim é que um navio (...) tendo recebido um impulso sobre si, muito tranquilo, mover-se-ia em torno do mesmo ponto sem parar, (...) se todos os obstáculos ou impedimentos pudessem ser removidos.

Com o que precede, Galileo mostra aos seguidores de Aristóteles que o movimento circular uniforme é tão "natura" - segundo a própria terminologia aristotélica - quanto o movimento retilíneo para os corpos de nosso mundo e consequentemente também para a Terra e para os planetas.

Nesse momento, Galileo já tinha percebido que a "ordenação perfeita" do universo somente era possível de duas maneiras: pelo repouso ou pelo movimento circular. Não mais - a distinção é fundamental - por uma razão estética, como em Aristóteles, mas simplesmente porque o movimento circular era o único que poderia conservar sempre semelhante a ele mesmo o sistema formado pelos corpos que giram (os planetas) e o centro em torno do qual giram (o Sol).

Assim é que, na Primeira Jornada do "Diálogo", Salviati disse que:

Disto parece-me que se pode muito razoavelmente concluir que, para a manutenção da ordem perfeita entre as partes do mundo, é preciso dizer que as partes móveis são móveis só circulamente, e se existem algumas que não se movem circularmente, estas por necessidade são imóveis; não existindo outra coisa, salvo o repouso e o movimento circular, apta à conservação da ordem (GALILEI, 2004, p. 112).

Considerando que o modelo coperniciano era precisamente constituído em torno de movimentos circulares, portanto, nada mais se opunha a que Galileo se sentisse convicto de sua veracidade e pronto a tentar convencer os outros.

É bem verdade que Galileo tinha observado o movimento de rotação própria do Sol por intermédio das suas observações das manchas solares, de modo que, a rigor, o Sol não estava em repouso. Mas ele tinha também observado que, na superfície da Terra, o movimento de rotação de uma esfera em torno de um diâmetro era um movimento "natura" nesse sentido que, uma vez iniciado, continuaria indefinidamente (se não houvesse atrito). O seu argumento era engenhoso. 
Consideremos uma esfera homogênea (Fig. 1) com um diâmetro fixo (eixo). A um elemento tal que "A" podemos sempre associar outro elemento, tal que "B", simétrico de "A" em relação ao eixo. Quando "A" está subindo (com "repugnância"), "B" está descendo (com "inclinação"). Entende-se que "repugnância" e "inclinação" possam se compensar, de modo que, no seu conjunto, a esfera continua girando, "indiferentemente".

Portanto, o movimento de rotação do Sol se enquadrava perfeitamente, no esquema acima. Aliás, o problema era o mesmo para a Terra; um idêntico argumento convencia Galileo que, além do seu movimento de translação circular, a Terra podia ter um movimento de rotação própria em torno do seu eixo: era o movimento diurno do modelo coperniciano (KUHN, 1990). No entanto, esse movimento diurno tinha sido, desde Aristarco, um obstáculo a qualquer modelo heliocêntrico, pelos argumentos físicos contra o qual esbarrava e que ninguém, até então, tinha conseguido derrubar. Era, portanto, a vez de Galileo envolver-se com os argumentos contra o movimento diurno.

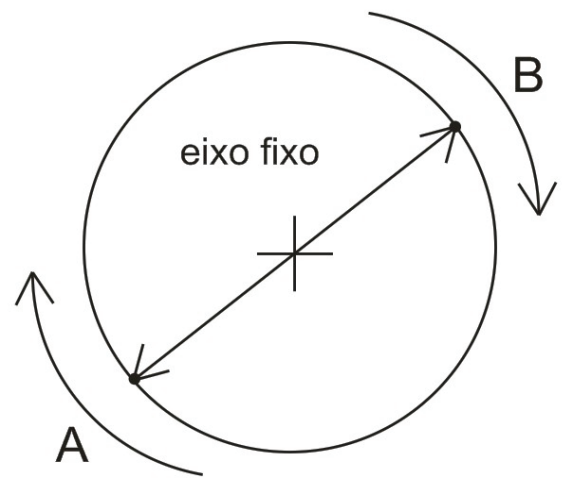

Fig. 1 - O movimento de rotação própria de uma esfera homogênea (ou de uma roda, ou de um disco), é também um movimento "natura". Assim, Galileo entende que o Sol também possui um movimento desse tipo.

\section{A refutação dos argumentos contra o movimento diurno}

Basicamente, os argumentos pertenciam a duas categorias distintas. Os da primeira categoria (pedra que cai do alto de uma torre, movimento das nuvens, movimento dos pássaros, tiro de canhão, etc.) baseavam-se no fato (pressuposto) de que um corpo terrestre provisoriamente separado do seu suporte (terrestre) não 
poderia acompanhar a Terra no seu pretenso movimento de rotação, atrasando-se para o oeste. Entretanto, nada disso acontece: a pedra largada do alto da torre cai ao pé da torre (e não a oeste) e assim por diante, para os outros fenômenos citados anteriormente.

Os de segunda categoria pertenciam aos efeitos da "força centrífuga". Se a Terra girasse em torno de seu eixo, não deixariam de se manifestar, "projetando" ao longe todos os objetos na superfície da Terra.

\section{1. Resposta galileana aos argumentos da primeira categoria}

Galileo segue praticamente a mesma resposta de Giordano Bruno, reforçando-a e sistematizando-a. Diz ele, na Segunda Jornada do "Diálogo", que um movimento não pode alterar as relações mútuas de um conjunto de corpos, desde que todos os corpos do conjunto participem daquele movimento.

Ele se refere novamente ao exemplo de um navio. Um observador terrestre sabe que o navio se movimenta em relação a Terra, mas um observador fechado no interior do navio não tem nenhum meio de saber se o navio está em repouso ou em movimento (supõe-se evidentemente um movimento uniforme sobre um mar tranquilo). Assim é que um objeto largado no navio cairá perpendicularmente ao convés, se largado do alto do mastro, cairá ao seu pé!

Acrescenta Galileo: uma torre está para a Terra assim como o mastro está para o navio. Para ele, o movimento circular "horizontal" é um movimento "indiferente" para os corpos e que não afeta, em nada, qualquer outro movimento que o corpo possa ter.

De modo que, continua ele, a pedra do alto da torre participa desse movimento de rotação "indiferente" de todos os corpos (inclusive a torre) na superfície da Terra. Ao ser largado, ele vai comportar-se em relação à torre como a pedra no navio se comporta em relação ao mastro: ele cairá ao pé; nem de um lado nem do outro, mas exatamente na vertical do ponto de largada.

O que Galileo acaba de enunciar no "Diálogo" - embora implicitamente é uma conservação do movimento circular em torno do centro da Terra e está claro que esse mesmo argumento de conservação explica (para Galileo) o movimento das nuvens, dos pássaros, do tiro de canhão, etc. que acompanham "naturalmente" o movimento da Terra, junto com o ar no qual se movem.

Assim como R. A. Martins discutiu em seu trabalho (MARTINS, 1994), vamos também verificar a seguir o que está errado nesse conceito.

$\mathrm{Na}$ análise do problema da queda, Galileo está duplamente errado. Em primeiro lugar, não há conservação do movimento circular. O que Galileo tem em 
mente é, propriamente, uma forma ainda imatura da "Lei da Inércia". O que, digase de passagem, ele não poderia utilizar, por ainda desconhecer os princípios físicos subjacentes ao fenômeno. Em segundo lugar, ainda que houvesse conservação do movimento circular, Galileo, em princípio, erraria outra vez ao afirmar que a pedra cai ao pé da torre. Com efeito, (Fig. 2) numa Terra em rotação, o ponto mais alto da torre - "A" (suposta no equador terrestre para simplificar o raciocínio), tem uma velocidade maior que ao pé da torre - "B". Se a pedra largada em "A" conserva a sua velocidade inicial horizontal, superpondo essa velocidade à velocidade de queda, ela adianta durante a queda, em relação ao ponto "B". Consequentemente, ela irá cair a leste do pé da torre, onde está o ponto ("B").

Na realidade, é efetivamente isso que acontece, embora esse "desvio para leste" seja muito pequeno para alturas de queda da ordem de uma torre. A solução exata do problema é difícil e somente seria dada cerca de 200 anos mais tarde, pelo matemático francês Gustave Gaspard Coriolis. Mas é curioso observar que, se Galileo tivesse interpretado corretamente a premissa (errada) da conservação do movimento circular, ele teria tido, no desvio para leste, um argumento positivo em favor do movimento diurno.

Embora errada, a resposta aos argumentos da primeira categoria contém essencialmente um fundo verdadeiro, que permite a Galileo dar, intuitivamente, uma "solução certa em primeira aproximação", como diríamos hoje. É perfeitamente correto, do ponto de vista experimental, que a pedra caia ao pé da torre, pois o pequeno desvio para leste, previsto pela teoria, não poderia provavelmente ter sido observado por ele. E é não menos verdadeira a afirmação de que a razão da pedra cair ao pé da torre (em "B"), se não é a conservação do movimento circular, é, no entanto, algo conceitualmente muito próximo à "Lei da Inércia".

\section{2. Resposta galileana aos argumentos da segunda categoria}

Nesse caso, Galileo foi muito menos feliz: faltava-lhe evidentemente uma Dinâmica, que, obviamente, ainda não existia. Vejamos, rapidamente, qual foi sua atitude em relação aos argumentos baseados na "força centrífuga" (para uma excelente crítica sobre esse tema veja o trabalho de R. A. Martins (MARTINS, 1994)).

A primeira observação de Galileo é que, se um corpo em movimento circular se solta do vínculo que o obrigava a esse movimento, é ao longo da tangente (e não do raio) que o corpo continuará a mover-se. Galileo nota que o corpo se afasta muito pouco da trajetória circular e esse afastamento inicial é tanto menor quanto maior for o raio da trajetória. Assim, ele nota que a circunferência terrestre 
é tão grande que a distância entre a circunferência e a tangente é ainda imperceptível a vários quilômetros do ponto de contato.

Isso posto, Galileo faz observar que, para impedir que um corpo se afaste ao longo de uma tangente a uma trajetória circular, basta aplicar-lhe uma força que anule os efeitos da tendência centrífuga. No caso da Terra, essa força, evidentemente, é a gravidade, o que Galileo não conseguiu intuir ou compreender.

Apesar da exposição de Galileo estar correta, é na sua conclusão que vai surgir o erro. Com efeito, Galileo atribui aos pontos da Terra velocidades lineares iguais (ao invés de angulares), concluindo que os efeitos centrífugos são inversamente proporcionais da distância ao centro.

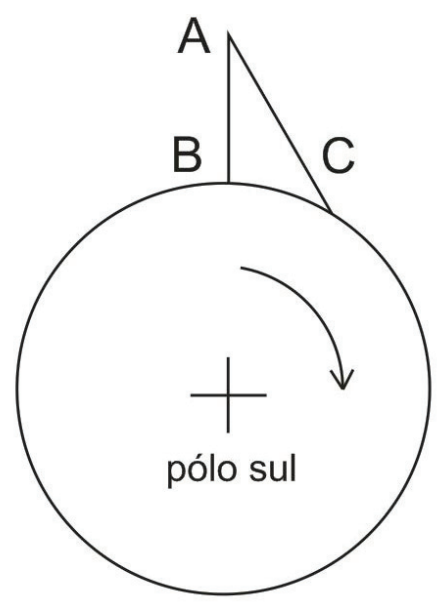

Fig. 2 - Para a Terra em rotação, o ponto mais alto da torre (" $A$ "), tem uma velocidade maior que ao pé da torre ("B"). Se a pedra largada em " $A$ " conserva a sua velocidade inicial horizontal, superpondo essa velocidade à velocidade de queda, ela adianta durante a queda em relação ao ponto " $B$ ". Consequentemente, ela irá cair à leste do pé da torre ("C").

Galileo afirma que o raio da Terra é tão grande que esses efeitos são muito pequenos e, como a tangente se confunde praticamente com o arco (sempre no caso da Terra), a gravidade é sempre suficiente para fazer voltar à superfície um corpo que tenderia a escapar tangencialmente. Dessa maneira, Galileo refuta o argumento ptolemáico dos efeitos centrífugos contra o movimento diurno. Porém, o raciocínio está incompleto, pois Galileo somente poderia ter refutado o argumen- 
to lançando mão de conceitos que ainda não tinham sido elaborados. A dinâmica de rotação só teria sido desenvolvida cerca de três décadas mais tarde por Christiaan Huygens e Isaac Newton.

\section{Surge o método científico}

Galileo tem a intuição que tanto a pergunta como as soluções do problema devem ser elaboradas numa linguagem especial: a linguagem matemática. É precisamente nisso que reside a chamada "Revolução Científica do Século XVII" (RONAN, 1987 ; KUHN, 2003).

Para que o fenômeno (observação) estudado possa ser tratado matematicamente, é necessário reduzi-lo a um conjunto de parâmetros suscetíveis de medição, a denominada construção do modelo físico (LUCIE, 1978). Esse modelo deve obedecer, decide o investigador, a certas leis ou teorias preexistentes. Se essas leis não existem, o investigador impõe ao modelo certas hipóteses de trabalho.

As leis ou hipóteses impostas ao modelo levam a certas deduções analíticas, que fornecem, no papel, uma resposta provisória à pergunta inicial e permitem geralmente fazer previsões verificáveis quanto às respostas a outras perguntas, porventura suscitadas pelo modelo, no decorrer da investigação.

No entanto, sendo as leis e as hipóteses de trabalho, imposições humanas, resta ainda saber se a natureza concorda com a resposta encontrada. Somente há um meio de sabê-lo: voltar à experiência e analisá-la criteriosamente. Somente ela permitirá decidir, por um lado, se o modelo físico construído era um modelo correto (isto é, se todos os parâmetros relevantes para a pergunta feita foram incluídos) e, por outro lado, se as leis ou hipóteses de trabalho que foram impostas ao modelo, são corretas.

Podemos resumir tudo isso sob a forma do diagrama esquemático apresentado a seguir.

O maior mérito de Galileo foi ter entendido, ou pressentido, que a chave do método científico estava precisamente na passagem abstrata do real inicial (observação) para o real final (experiência). Essa "ponte" está contida no esquema acima através do quadro tracejado.

A linguagem utilizada por Galileo (como aliás, mais tarde por Newton) era a geometria. Ele ainda não possuía os recursos os quais chamamos hoje de análise matemática (a algébrica e a análise vetorial), que iria começar a ser desenvolvida por Gottfried Leibnitz e pelo próprio Isaac Newton, no século XVII. 
Acontece que a manipulação correta da linguagem geométrica é uma verdadeira arte, quase totalmente em desuso hoje em dia; por outro aspecto, a análise oferece melhores condições para sistematização, o que fornece uma razoável garantia de sucesso na solução dos problemas.

Apenas como exemplo de uma aplicação do método científico, podemos colocar a seguinte situação: não é óbvio que, na ausência de resistências de atrito ou do ar, os corpos caiam com velocidade uniformemente crescente com o passar do tempo, independentemente de seu peso, forma ou tamanho. Partindo dessa conjectura, deduzir que (de preferência com o uso da matemática), se os corpos caírem com velocidade uniformemente acelerada, sem sofrer qualquer resistência, os deslocamentos percorridos em intervalos de tempo iguais estarão entre si como os números ímpares: $1,3,5,7,9, \ldots$ Isto é, no instante igual a um segundo a esfera cai e encontra-se a uma altura "h"; ao fim de dois segundos, "4h" (pois temos: $\mathrm{h}+$ $3 \mathrm{~h}$ ); ao fim do terceiro segundo, " $9 \mathrm{~h}$ " (no caso: $4 \mathrm{~h}+5 \mathrm{~h}$ ); e assim por diante.

Para verificar essa conclusão, realiza-se uma experiência dedicada ao fenômeno, ou seja, um experimento organizado e interpretado de acordo com a conjectura. Por exemplo, poderíamos montar um plano inclinado e sobre ele deixar rolar uma esfera, ao invés de deixá-la cair livremente. Dessa forma, reduz-se sensivelmente a influência da resistência do ar. Por outro lado, se a canaleta do plano estiver bem polida e a esfera for lisa e maciça, é possível diminuir mais ainda o atrito de contato. Então, dividindo as alturas do plano inclinado segundo os valores: $1,3,5,7,9, \ldots$ A partir dessa montagem, deixamos rolar a esfera e, se ao medir os tempos para percorrer as alturas assinaladas forem iguais, então podemos deduzir que a conjectura será verdadeira.

Nas experiências realizadas por Galileo repetidas vezes, os resultados foram esses. O que o levou a constatar que a conjectura é verdadeira, ou seja, os corpos caem com velocidade uniformemente acelerada.

É exatamente esse o método científico: o da verificação experimental de uma conjectura, a qual pode ser, inclusive, contrária a toda evidência, e não precisa ser necessariamente induzida de fenômenos observados. Torna-se verdadeira se o experimento com ela concordar.

O método científico foi tão revolucionário que transformou a ciência na maneira de estudar os fenômenos observados e estabeleceu novos paradigmas, segundo afirmaria $\mathrm{Th}$. S. Kuhn no seu livro A estrutura das revoluções cientificas (KUHN, 2003). 


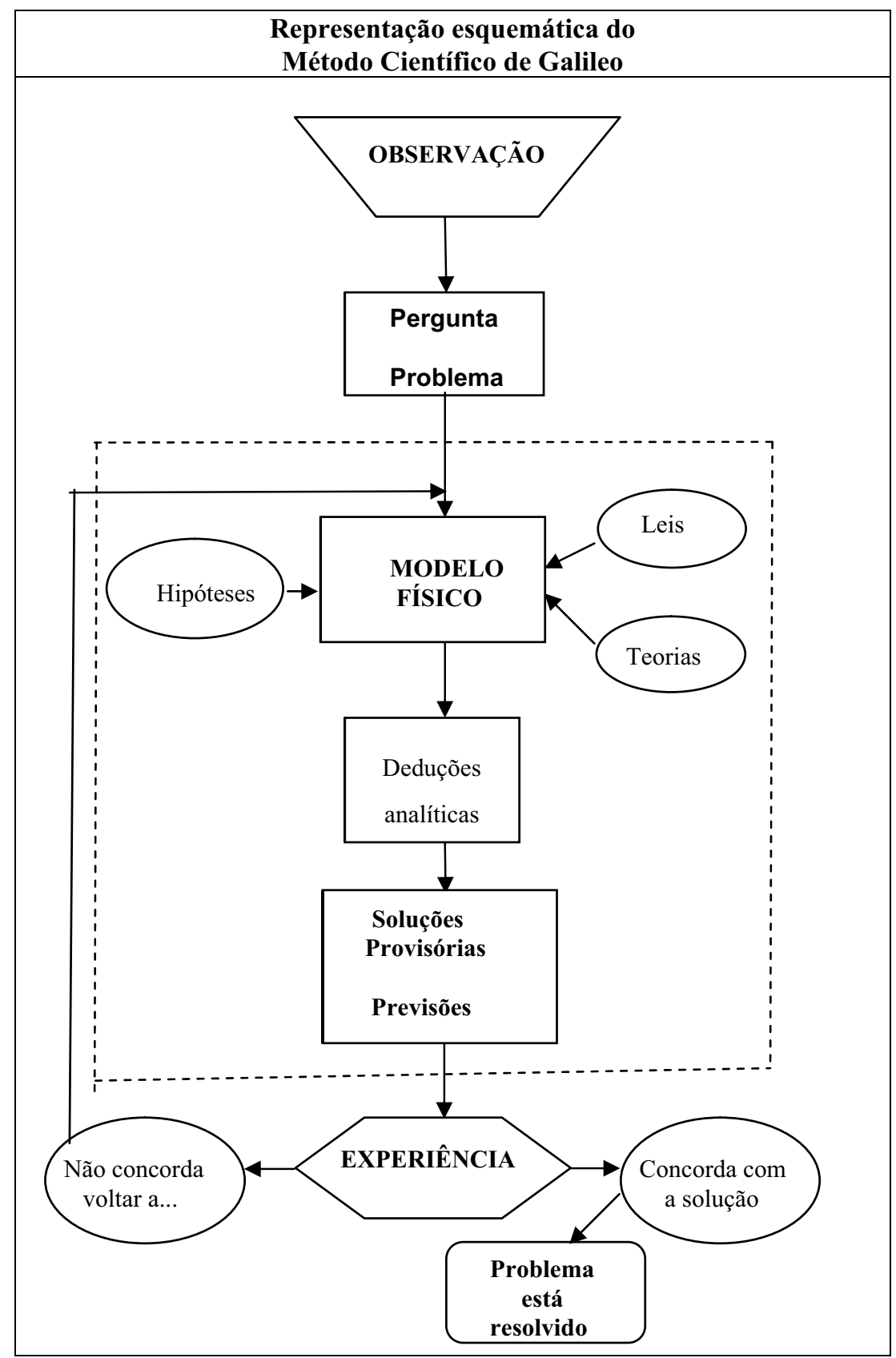

Cad. Bras. Ens. Fís., v. 26, n. 1: p. 173-198, abr. 2009. 


\section{Discussão}

Antes de terminarmos esse sumário da luta de Galileo em prol do copernicianismo e sua visão (aqui discutida de forma parcial e limitada) a respeito do universo, é bom lembrar que muitas perguntas surgem e muitas dúvidas ainda permanecem no meio científico.

Algumas dessas perguntas e dessas dúvidas são, para nós, estéreis, porque meramente especulativas, por exemplo, será que os quase 30 anos de esforços e polêmicas que culminaram com a angústia e o medo, além de um processo em desgraça submetido aos juízes do Tribunal do Santo Ofício (Inquisição), conseguiram convencer os contemporâneos de Galileo da validade do copernicianismo?

O que realmente importa é o fato de que, depois de Galileo, nenhum dos homens que se sobressaíram no desenvolvimento da ciência, jamais colocaram em dúvida o heliocentrismo. Em que pese a exigência de uma nova física para explicar muitas outras questões. Nesse particular, é provável que as descobertas astronômicas de Galileo tiveram muito mais peso que as suas refutações dos argumentos contra o movimento diurno. Como observamos, essas refutações ainda se ressentiam da falta de uma mecânica mais elaborada. Isso é justamente o que a defesa do copernicianismo trouxe de positivo para a elaboração dessa mecânica que devemos ressaltar.

Em primeiro lugar, a eclosão do conceito de sistema inercial, isto é, de um sistema cujo movimento próprio é sem efeito (é "indiferente") para os movimentos relativos dos vários corpos que o compõem. O movimento do navio mostra que Galileo sentiu, fisicamente, o que era um sistema inercial. Embora sem enunciar formalmente o princípio clássico da relatividade, não parece haver dúvidas que ele entendeu claramente que um movimento de translação uniforme do conjunto não influencia os movimentos relativos dos corpos contidos no sistema, seguindo-se necessariamente que nenhuma experiência mecânica conduzida no sistema poderá detectar o seu movimento de translação.

Não restam dúvidas de que Galileo cometera muitas falhas. Talvez a mais grave de todas tenha sido uma falha conceitual: no seu entendimento, a translação do sistema era uma translação circular em torno da Terra. Sabemos hoje que a melhor definição de um sistema inercial em mecânica clássica é a de um sistema ligado a um corpo considerado livre. Mas é difícil culpar Galileo por ter pensado do jeito que pensou e não ter podido abstrair a onipresente gravidade. Para Galileo, um corpo sem gravidade era simplesmente impensável e, nessas condições, um movimento inercial retilíneo é evidentemente impossível. 
Depois do sistema inercial, a contribuição mais importante que a defesa do copernicianismo trouxe foi o conceito de conservação do movimento. Mais uma vez, o pensamento de Galileo não foi inteiramente correto. O seu "princípio de conservação" referia-se a um movimento circular uniforme em torno da Terra. Não restam dúvidas que, também nesse ponto, a sua intuição foi surpreendente. E nesse aspecto, pouco importa que as origens do pensamento galileano se encontrem provavelmente no conceito medieval de impulsão.

A contribuição de Galileo foi decisiva por ter ele entendido que o movimento uniforme é um estado, indiferenciável conceitualmente do repouso e que consequentemente se perpetua, como o repouso, a menos que um agente externo venha a perturbá-lo. Nisso está a chave da "Lei da Inércia" que os sucessores de Galileo enunciaram, mais comodamente que antes deles. Galileo tinha "vivido" essa lei, embora não a enunciasse, pois não sabia como fazê-lo.

Finalmente, a defesa do copernicianismo implicava a aceitação da composição de movimentos. A Terra tem um duplo movimento: translação circular em torno do Sol (movimento anual) e rotação em torno do eixo dos pólos (movimento diurno). Esses dois movimentos se associam, se compõem, cada um deles agindo como se o outro não existisse. Essa foi a sua maior colaboração para a posterior aceitação da obra maior de Nicolaj Kopernik (COPÉRNICO, 1984), apesar de suas concepções terem sido ainda intermediárias entre o pensamento de Aristóteles e o de Isaac Newton.

Essa composição de movimentos se introduzia implicitamente no pensamento galileano ao mesmo tempo em que desaparecia o conceito aristotélico do "movimento-processo", cedendo o lugar ao do "movimento-estado". A partir do momento em que Galileo entende que o movimento não afeta em nada o corpo, que ele é indiferente à natureza do corpo, em outras palavras, que determinado movimento não é específico de determinado corpo, então nada impede que um mesmo corpo possa ter vários movimentos simultâneos. Esses movimentos não podem se tolher mutuamente, já que o corpo, intrinsecamente, a todos ignora.

\section{Conclusão e perspectivas}

É importante lembrar que, de modo algum, Galileo conseguiu apresentar uma teoria física completa e satisfatória em favor do copernicianismo (KOESTLER, 1989 ; KUHN, 1990). Ele não conseguiu responder a todas as objeções da época contra os movimentos da Terra. As questões e dificuldades encontradas por ele e aqui discutidas permitem mostrar e ilustrar pontos conceituais que 
podem confundir as pessoas envolvidas com ciências. Esses pontos podem ser abordados pelo professor, que deve ser capaz de estimular os estudantes e discutir os conceitos envolvidos, aprofundando-os nesse assunto relacionado à história do desenvolvimento científico.

Sob o ponto de vista didático, a discussão sobre as dificuldades encontradas por Galileo para explicar os movimentos da Terra devem ser aproveitadas pelo professor em suas atividades com os estudantes. Para tanto, é necessário que o professor se envolva com os aspectos históricos da física medieval. Nesse sentido, há alguns trabalhos de excelente qualidade nas referências abaixo citadas (RONAN, 1987; GALILEI, 1987; KOESTLER, 1989; MARTINS, 1994; GALILEI, 2004 ; KOYRE, 2006).

Uma outra excelente oportunidade para promover esses e outros pontos de discussões é a partir de agora, uma vez que o ano de 2009 foi declarado pela IAU - International Astronomical Union, com sede em Paris (UAI - União Astronômica Internacional) e, com apoio da UNESCO, órgão da ONU (Organização das Nações Unidas) para Educação, Ciência e Cultura, como $\underline{O}$ Ano Internacional da Astronomia (IYA-2009 - International Year of Astronomy 2009), em comemoração aos 400 anos das primeiras observações telescópicas realizadas por Galileo e a concepção do método científico.

O IYA-2009 será uma celebração global da astronomia e de suas contribuições para a ciência e humanidade, com ênfase na educação e no envolvimento de pessoas, particularmente dos jovens.

Várias atividades serão organizadas em escala global, incluindo observações públicas com telescópios, atividades educativas, seminários, palestras em escolas, universidades, exposições, sessões especiais em Planetários e Observatórios. Além disso, serão propostas atividades artísticas e culturais, programas dirigidos à crianças, jovens e professores.

Cerca de 200 países irão aderir ao IYA-2009. No Brasil o Comitê de Coordenação para os eventos é presidido pelo Prof. Dr. Augusto Damineli, do Instituto de Astronomia, Geofísica e Ciências Atmosféricas da USP (Universidades de São Paulo, São Paulo). O endereço eletrônico para o IYA-2009, onde o leitor poderá obter maiores informações é: http://www.astronomia2009.org.br.

\section{Agradecimentos}

O autor gostaria de expressar seus agradecimentos aos árbitros pelas considerações apreciativas, comentários, reformulações e sugestões apresentadas no decorrer do preparo deste trabalho e à PUC-Campinas e ao IFGW-UNICAMP pelo 
apoio e possibilidade de poder desenvolver este trabalho. Meus especiais agradecimentos a Prof ${ }^{a}$. Ana Maria de Almeida Maluf e ao Prof ${ }^{\circ}$. Orlando Rodrigues Ferreira e a Márcia de Britto pelas revisões do manuscrito e pelas sugestões apresentadas.

\section{Referências bibliográficas}

ARISTÓTELES. On the heavens (De cælo). Tradução: STOCKS, J. L. In: Hutchins, R. M. (Ed.) Great books of the western word. Chicago: Encyclopaedia Britannica, v. 8, 1952, p.359-405.

CAVAlCANTE, P. O novo mundo de Galileu. Super Interessante, São Paulo, ano 3, n. 5, p.72-77, maio 1989.

CLAVELIN, M. La philosophie naturelle de Galilée. Paris : Ed. Albin Michel, 1996. 508p.

COPÉRNICO, N. As revoluções do orbes celestes. Tradução : A. Dias Gomes e Gabriel Domingues. Lisboa: Editora Fundação Calouste Gulbenkian, 1984. 657p.

GALILEI, G. O ensaiador. Os Pensadores. v. XII. Tradução e notas: Helda Barraco. São Paulo: Abril Cultural e Industrial, 1973. p.99-238.

GALILEI, G. Diálogo sobre os dois máximos sistemas do mundo ptolomáico e copernicano. Tradução, introdução e notas: Pablo Rúben Mariconda. 2. ed. São Paulo: Imprensa Oficial, 2004. 882p.

GALILEI, G. Duas novas ciências. Tradução: L. Marioconda e Pablo Rúben Mariconda. 2. ed. São Paulo: Ched Editorial/Nova Stella/ Instituto Italiano di Cultura, 1985. 315p.

GALILEI, G. A mensagem das estrelas. Rio de Janeiro: Editora Salamandra. Coleção Clássicos da Ciência (1), MAST (Museu de Astronomia e Ciências Afins), 1987. 72p.

HALL, A. R. A revolução na ciência: 1500-1750. Tradução: Maria Teresa Louro Pérez. Lisboa: Edições 70, 1988. 496p.

KOESTLER A. O homem e o universo. São Paulo: Editora IBRASA, 1989. 426p. 
KOYRÉ, A. Estudos galilaicos. Tradução de N. F. da Fonseca. Lisboa: Editora Dom Quixote, 1992. 426p.

KOYRE, A. Do mundo fechado ao universo infinito. 4. ed. Rio de Janeiro: Editora Forense Universitária, 2006. 304p.

KUHN, T. S. A revolução copernicana. Tradução: Maria Costa Fontes. Lisboa: Edições 70, 1990. 261p.

KUHN, T. S. A estrutura das revoluções científicas. Tradução Beatriz Vianna Boeira e Nelson Boeira. 7. ed. São Paulo: Perspectiva, 2003. 262p.

LUCIE, P. A gênese do método científico. 2. ed. Rio de Janeiro: Editora Campus, 1978. 149 p.

MARTINS, R. A. Galileo e a rotação da Terra. Caderno Catarinense de Ensino de Física, Florianópolis, v. 11, n. 3: p.196-211, dez.1994.

NASCIMENTO, C. A. R. Para ler Galileu Galilei - Diálogo sobre os dois máximos sistemas do mundo. 2. ed. São Paulo: EDUC, 2003. 105p.

PEDUZZI, L. Q. O. A Física de Galileu. In: Força e movimento: das ideias de Aristóteles às leis de Newton. Florianópolis: Editora da UFSC, versão preliminar, mar. 1991

RONAN, C. A. História ilustrada da ciência. Tradução: Jorge Enéas Fortes. v.III. São Paulo: Jorge Zahar Editor (Círculo do Livro), 1987. 136p.

SHEA, W. La révolution galiléenne. Paris: Editions du Seuil, 1992. 314p. 